Research Article

\title{
Fast and Versatile Pathway in Fabrication of Polyelectrolyte Multilayer Nanofiltration Membrane with Tunable Properties
}

\author{
Ahmad M. Alghamdi (iD \\ Chemical Engineering Department, Imam Mohammad Ibn Saud Islamic University, Riyadh 11432, Saudi Arabia \\ Correspondence should be addressed to Ahmad M. Alghamdi; amsalghamdi@imamu.edu.sa
}

Received 18 March 2021; Revised 15 May 2021; Accepted 1 June 2021; Published 11 June 2021

Academic Editor: Ibrahim H. Alsohaimi

Copyright (c) 2021 Ahmad M. Alghamdi. This is an open access article distributed under the Creative Commons Attribution License, which permits unrestricted use, distribution, and reproduction in any medium, provided the original work is properly cited.

\begin{abstract}
Thin film composite nanofiltration (NF) membranes are relatively new membranes compared to other types of pressure-driven membranes. However, they attract interest from researchers due to their versatility to be used in various applications. In this work, a new class of NF membrane was successfully fabricated through spin-assisted layer-by-layer assembly by depositing alternate layers of branched polyethylenimine (PEI) and poly(sodium 4-styrenesulfonate) (PSS) on ultrafiltration polysulfone (PSF) membrane. The suitability of the fabricated membranes for removal of divalent ions was investigated. It was found that the membrane consisting of (PEI/PSS) $10^{-} 0.05 \mathrm{M} \mathrm{NaCl}$ showed $\mathrm{MgCl}_{2}$ rejection rate of $93.95 \%$ and permeation flux of $0.9 \mathrm{~L} / \mathrm{m}^{2} \cdot \mathrm{h} \mathrm{bar}$ during tests performed using a crossflow permeation cell at a crossflow velocity of $0.65 \mathrm{~m} / \mathrm{s}, \mathrm{MgCl}_{2}$ feed concentration of $6530 \mathrm{ppm}$, pressure of $10 \mathrm{bar}$, temperature of $32.5^{\circ} \mathrm{C}$, and $\mathrm{pH}$ of 6.5 . This result suggests that this new fabrication method is suitable for producing polyelectrolyte multilayered (PEM) NF membranes that exhibit comparable membrane performance to commercial ones.
\end{abstract}

\section{Introduction}

Among pressure-driven membranes, a nanofiltration (NF) membrane is considered as the most recently developed one. The NF membrane is known for its ability to reject multivalent ions and organic compounds coupled with high permeation flux. Owing to these characteristics, the use of NF particularly in water treatment becomes more and more popular particularly in water treatment applications such as removal of multivalent ions $[1,2]$, heavy metals [3-5], pesticides [6,7], dyes [8], and textiles [9].

As for other pressure-driven membranes, NF also suffers from fouling. Rapid fouling film formation causes significant flux decrease which can hurt the operation of this membrane especially in terms of operational cost. In severe cases, it even becomes necessary to replace the membrane. Membrane cleaning and replacement account for up to $6 \%$ and $16 \%$, respectively, of the total water treatment costs [10]. Thus, improving the fouling resistance of these membranes has become essential for reducing the above-described costs.
It is generally accepted that the physicochemical properties of membranes, such as their roughness, surface charge, foulant-membrane surface interactions, and hydrophobicity, are the primary factors affecting their fouling characteristics. The primary source of these problems is the membrane material itself. Several common commercial polymers such as poly(ether sulfone) (PES), polyamide (PA), and poly piperazine amide (PPA) are used extensively for $\mathrm{NF} /$ reverse osmosis (RO) membranes, making up $91 \%$ of the total sales [11]. For instance, PA is used by GE-Osmonics to produce Desal $5 \mathrm{DL}^{\circledR}, \mathrm{NF}^{\circledR}{ }^{\circledR}$, and Desal $51 \mathrm{HL}^{\circledR}$; meanwhile, PES is used by Nitto Denko to fabricate NTR7450 ${ }^{\circledR}$, whereas PPA is used by Toray and Film Tech to prepare UTC-20 ${ }^{\circledR}$ and NF- $400^{\circledR}$, respectively.

All these membranes, and particularly polyamide membranes, are hydrophobic and exhibit relatively rough surfaces. As a result, these NF membranes are especially susceptible to fouling. Unfortunately, research on commercial Reverse Osmosis (RO)/NF membranes from a chemistry viewpoint has been stagnant for some time now, 
with there being no major developments in the last couple of decades $[11,12]$.

It is suggested that, with respect to fouling, both the membrane chemistry and the fabrication technique used play a significant part, as they have a determining effect on the physicochemical properties of the membrane in question. Thus, research efforts in the last two decades have primarily been directed toward the development of novel membrane materials, including inorganic ones, as well as those incorporating nanoparticles and polymers with high hydrophilicity and having smooth surfaces [11].

In order to tackle both fabrication technique and membrane chemistry all at once, it is imperative to try out several new emerging thin film fabrication techniques that truly provide access to control the properties of the film to nanoscale and also offer flexibility from chemistry point of view. Among thin film fabrication techniques, layer-by-layer (LbL) assembly is considered to be the most versatile and most robust technique [13].

In LbL assembly, ultrathin layers with thicknesses of the order of the subnanometer scale can be deposited alternately on a support layer. Hence, the final thickness of the active layer can be fine-tuned to the desired level merely by varying the number of deposition cycles. One can also easily change the membrane surface charge by terminating the assembly process at the deposition of a material with the desired charge (positive, negative, or neutral). For this purpose, typically polyelectrolyte is employed because they are typically hydrophilic and exhibit a charge either positive or negative. This technique itself can utilize various materials including organic, inorganic, or even microorganism.

Principally, there are three approaches for fabricating LbL-assembled films, namely, dipping, spraying, and spinning. Spin-assisted LbL (SA-LbL) assembly is believed to be the fastest method and also the most suitable one for producing membranes with the smoothest surfaces [14, 15]. There have been several works done for the use of conventional dip-LbL in NF application [16-25]; meanwhile, the use of SA-LbL assembly for fabrication of NF membrane is still at infancy. However, our previous works showed that SA-LbL can be successfully used to fabricate this membrane with outstanding properties [26-29].

Based on the above literature review, in this work, spinassisted LbL (SA-LbL) assembly is utilized for fabricating NF membranes suitable for removing divalent salts such as $\mathrm{MgCl}_{2}$ from water. Also, as part of continuous work in finding the most suitable materials that provide high rejection, high flux, and less susceptible to biofouling, two other polyelectrolytes are used, namely, polystyrenesulfonate (PSS) and poly(ethylene imine) (PEI). Number of layers and $\mathrm{pH}$ assembly of polyelectrolyte were studied since PEI is weak polyelectrolyte whose degree of ionization is strongly affected by assembly and external $\mathrm{pH}$.

\section{Materials and Methods}

2.1. Materials. In this work, branched-polyethylenimine (PEI) with molecular weight of 25,000 and poly(sodium 4- styrenesulfonate) (PSS) with a molecular weight of 70,000 in the form of a $30 \mathrm{wt} \%$ in $\mathrm{H}_{2} \mathrm{O}$ solution were purchased from Sigma-Aldrich (USA). Extra-pure $\mathrm{NaCl}$ was obtained from Scharlau (Spain) while extra-pure $\mathrm{MgCl}_{2} \bullet 6 \mathrm{H}_{2} \mathrm{O}$ was obtained from Loba Chemie Pvt. Ltd. (India).

Stock solutions containing $0.02 \mathrm{M}$ polyelectrolytes (PEI and PSS) containing additional $\mathrm{NaCl}$ concentration of $0.05 \mathrm{M}$ were prepared. In these experiments, the $\mathrm{pH}$ of the PEI and PSS solution were varied to find the optimum condition for membrane preparation.

Polyethersulfone (PES) ultrafiltration (UF) membranes (YMPWSP3001, Sterlitech Corp., USA) with a pore size corresponding to a molecular weight cutoff of $10 \mathrm{kDa}$ were used as the support layers for fabricating the PEM TFC membranes. The PES UF membranes were tested and were found to exhibit a permeation flux of $235.7 \mathrm{~L} / \mathrm{m}^{2} \cdot \mathrm{h}$ at a pressure of $10 \mathrm{bar}$ and temperature of $33.5^{\circ} \mathrm{C}$. The molecular structures of the various materials used are shown in Figure 1.

2.2. Fabrication of PEM TFC Membranes. The prepared PEI and PSS solutions were alternately deposited on the PES UF membranes using a spin coater (POLOS SPIN150i ${ }^{\circledR}$, SPS Inc.). Prior to deposition, the PES UF support membrane was pretreated in an air plasma using a plasma cleaner (PDC-32G-2, Harrick Plasma Inc.) as per a procedure described elsewhere [30]. PEI was deposited firstly on the spinning PES support as the first layer. PSS layer was subsequently deposited in a similar manner to complete one cycle of bilayer deposition. The deposition process was performed at a speed of $3000 \mathrm{rpm}$; this speed was chosen based on a previous study [26], as it helped reduce the gradient in the radial thickness from the center of the support [31]. The PEI and PSS solutions were both deposited at a rate of $0.2 \mathrm{~mL} / \mathrm{s}$ for $10 \mathrm{~s}$, and the film was let to spin-dried for another $20 \mathrm{~s}$ afterward. After every polyelectrolyte deposition, the relatively dry film was then rinsed with deionized (DI) water at a rate of $0.4 \mathrm{~mL} / \mathrm{s}$ for $20 \mathrm{~s}$ to remove any weakly bonded polyelectrolyte molecules that might remain on the surface. This was followed by spin-drying for $20 \mathrm{~s}$. The resulting membranes were labelled as (PEI/PSS) $x$ where " $x$ " indicates the number of bilayers. The $\mathrm{NaCl}$ concentration in the two polyelectrolyte solutions were the same at $0.05 \mathrm{M}$ optimized value from our previous work $[28,29]$.

2.3. Permeation Tests. Permeation tests were performed using a crossflow permeation cell (Innovator ${ }^{\circledR}$ CF016, Sterlitech Corporation). The CF016 system has an active membrane surface area of $20.6 \mathrm{~cm}^{2}$. The conditions for the permeation tests were as follows: pressure of 10 bar, feed temperature of $32.39 \pm 0.27^{\circ} \mathrm{C}$, cross flow velocity (CFV) of $0.65 \mathrm{~m} / \mathrm{s}$, and $\mathrm{MgCl}_{2}$ concentration of $6578.21 \pm 69.2 \mathrm{ppm}$. Meanwhile, the $\mathrm{pH}$ of the feed solution remained stable at approximately $6.49 \pm 0.11$ without requiring any adjustments. These tests were performed for $5 \mathrm{~h}$, and the operation conditions were measured every hour. 


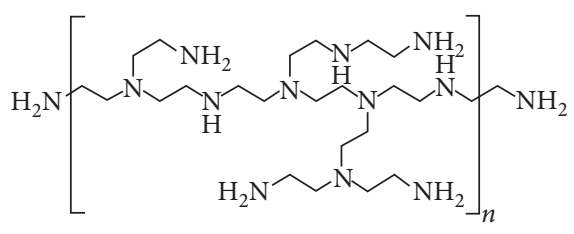

(a)<smiles>CC(C)(C)C(c1ccc(S(=O)(=O)O[Na])cc1)C(C)(C)C</smiles>

(b)

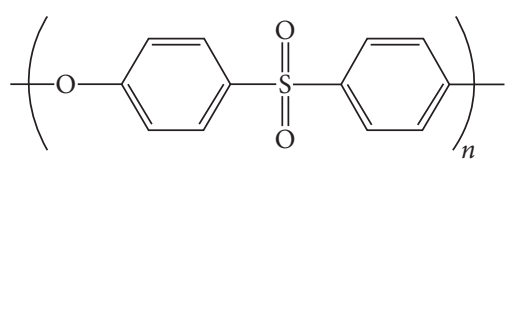

(c)

FIgUre 1: Molecular structures of materials used to synthesize PEM TFC membranes: (a) PEI, (b) PSS, and (c) PES.

\section{Results and Discussion}

PEM membranes consisting of branched PEI/PSS bilayers were fabricated utilizing SA-LbL assembly method on PES UF membrane supports. The resulting membranes were similar to TFC membranes. The multilayer PEI/PSS acted as the active layer for rejecting the salt, while the UF PES support provided the mechanical strength to the overall membrane structure. PSS is a strong polyelectrolyte with a $\mathrm{pKa}$ of 2.1 at room temperature [32], and its degree of ionization remains constant over a wide range of $\mathrm{pH}$ values [33], whereas PEI is weak polyelectrolyte which means the degree of ionization is strongly affected by its $\mathrm{pH}$.

3.1. Effect of Assembly $p H$ on Membrane Performance. As previously mentioned, PEI dissociation in an aqueous solution is a function of $\mathrm{pH}$; meanwhile, the dissociation of polyelectrolyte affects its conformation and multilayer structure. Thus, it is imperative to investigate the effect of assembly $\mathrm{pH}$ on membrane performance, i.e., permeate flux and rejection rate. In this work, not only assembly $\mathrm{pH}$ of PEI solution was studied, but also that of PSS and the rinse solution were studied too. Previous study by Lutkenhaus et al. [34] provides a valuable in-depth analysis for the effect of assembly $\mathrm{pH}$ of linear PEI (LPEI) on structure of polyelectrolyte multilayer consists of LPEI/PAA.

Figure 2 shows significant improvement of permeability without severely compromising the rejection rate of the membrane when the assembly $\mathrm{pH}$ of PEI was kept at 3.5 and that of PSS was changed from 8 to 3.5. This trend is even more pronounced when the water rinse $\mathrm{pH}$ was also brought to the same level. This trend implies that external $\mathrm{pH}$ also affects the conformation of already deposited PEI.

When the assembly $\mathrm{pH}$ of PEI was at 3.5, PEI was in highly ionized state and adopted less coiled conformation; meanwhile, PSS will always have highly flat conformation owing to its fully ionized condition at all $\mathrm{pH}$.

The combination of both polyelectrolytes at the $\mathrm{pH}$ for $\mathrm{PEI} / \mathrm{PSS} /$ water of $3.5 / 8 / 7$, respectively, is expected to show PEM with higher permeability. However, in fact, it showed the lowest permeability. This observation showed that the external $\mathrm{pH}$ also has significant impact. The water and PSS that carry more basic $\mathrm{pH}$ will penetrate the already deposited PEI layer and alter PEI ionization state to be less ionized. This results in changing of internal structure and increase of layer thickness. In the end, it provides more barrier for water transport across the film. The opposite behavior was noticed when the $\mathrm{pH}$ of rinsing water and PSS were adjusted at the same $\mathrm{pH}$ as that of PEI. In this case, PEI chain conformation remains flat and results in higher permeability, whereas when the $\mathrm{pH}$ of PEI was adjusted at more basic $\mathrm{pH}$, PEI chain became less ionized and adopted more coiled structure. Therefore, PEM film became thicker and provided less permeability.

Rejection mechanism of the NF membrane is somewhat more complex, particularly for charged solutes as used in this work. It is generally known that there are two contributing mechanisms, i.e., Donnan potential and steric hindrance in the rejection of charged solutes. When the layer was prepared from less ionized PEI, more PEI molecules are needed to compensate the charges of fully ionized PSS. This results in denser film compared to that prepared from highly ionized PEI. The denser film produces higher salt rejection.

\subsection{Effect of Number of Bilayers on Membrane Performance.} Number of bilayers deposited on membrane is also important parameter which determines the membrane performance. Figure 3 shows the changes in the permeation flux and salt rejection rate as the number of bilayers was increased from 5, 8, 10, and then 20 . It shows that as the number of bilayers was increased, the permeate flux decreased. The flux decline can be affected by several things such as layer thickness, effective pore radius, and porosity. However, layer thickness contributes the most significant effect. It is generally known that the permeation flux is inversely proportional to the membrane thickness. Thus, when more layers were added, the layer thickness increased and that resulted in the decrease of the flux. The flux decrease then becomes stagnant as more number of layers were deposited, implying the linear growth of PEI/PSS film as reported somewhere else [35].

Figure 3 also shows the increase of rejection rate as the number of layers was increased. This trend was due to improvement in surface coverage. This study also suggests that steric hindrance and Donnan potential play an important role in rejection mechanism in the case of NF membrane. Donnan potential effect has already taken place regardless of the number of layers; meanwhile, the steric hindrance effect becomes more evident as the surface coverage and layering quality improved through more layer deposition. This rejection still improved up to a certain number of layers, i.e., around 10 bilayers, and became 




Figure 2: Effect of solution $\mathrm{pH}$ on performance of (PEI/PSS) ${ }_{35}$ (testing condition: $P=10 \mathrm{bar}, T=32.08 \pm 0.3^{\circ} \mathrm{C}, \mathrm{CFV}=0.65 \mathrm{~m} / \mathrm{s}, \mathrm{MgCl}{ }_{2}$ concentration $=1345.6 \pm 66.6 \mathrm{ppm}$, and $\mathrm{pH}=6.52 \pm 0.06)$.

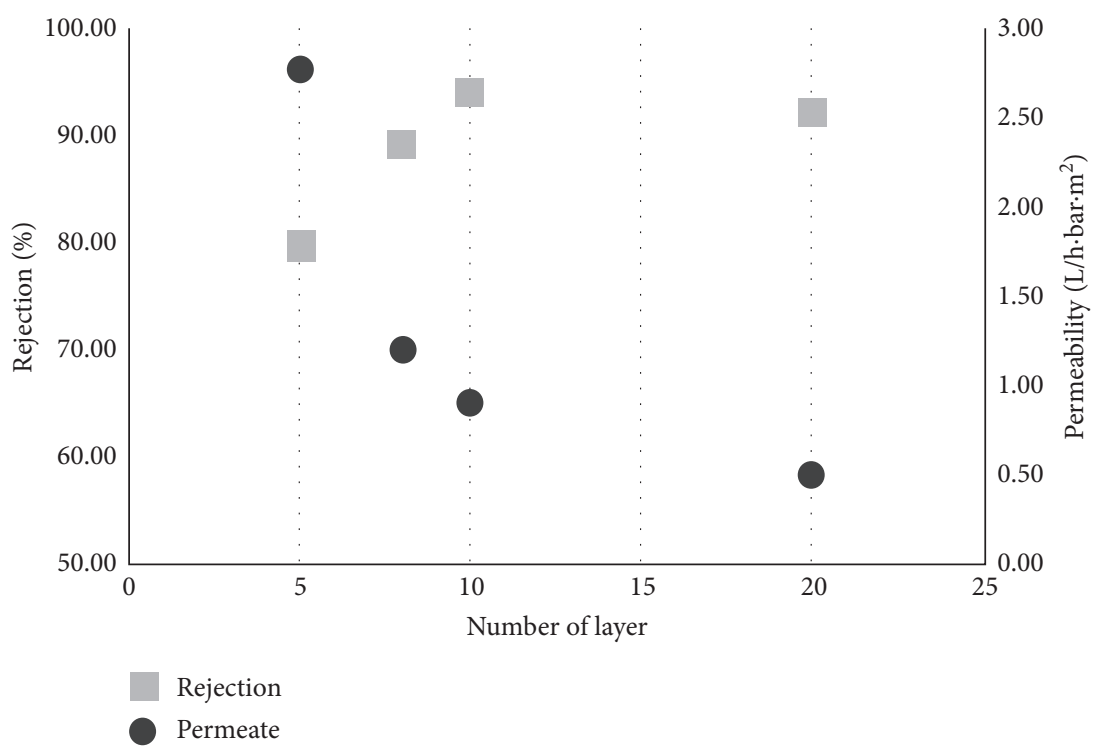

Figure 3: Effect of number of deposited PEI/PSS bilayers on salt rejection rate and permeability $\left(P=10 \mathrm{bar}, T=32.39 \pm 0.27^{\circ} \mathrm{C}\right.$, $\mathrm{CFV}=0.65 \mathrm{~m} / \mathrm{s}, \mathrm{MgCl}_{2}$ concentration $=6578.21 \pm 69.29 \mathrm{ppm}$, and $\left.\mathrm{pH}=6.49 \pm 0.11\right)$.

TABLE 1: NF membrane performance comparison.

\begin{tabular}{|c|c|c|c|c|c|}
\hline Membrane material & Preparation method & $\begin{array}{c}\text { Rejection } \\
(\%)\end{array}$ & $\begin{array}{l}\text { Permeability } \\
\left(\mathrm{L} / \mathrm{m}^{2} \cdot \mathrm{h} \text { bar }\right)\end{array}$ & Testing condition & Reference \\
\hline$(\mathrm{PEI} / \mathrm{PSS})_{35}-\mathrm{PES}$ & Spin & 93.8 & 1.05 & $\begin{array}{c}10 \text { bar, } 1345 \mathrm{ppm} \\
\mathrm{MgCl}_{2} .\end{array}$ & This work \\
\hline$(\mathrm{PEI} / \mathrm{PSS})_{10}$-PES & Spin & 93.5 & 0.9 & $\begin{array}{c}10 \mathrm{bar}, 6600 \mathrm{ppm} \\
\mathrm{MgCl}_{2} .\end{array}$ & This work \\
\hline$(\mathrm{PVA} / \mathrm{PVS})_{60}-\mathrm{PAN} / \mathrm{PET}$ & Dip & 98.5 & 0.089 & $\begin{array}{c}10 \text { bar, } 952.1 \mathrm{ppm} \\
\mathrm{MgCl}_{2} .\end{array}$ & {$[17]$} \\
\hline $\begin{array}{l}(\mathrm{PSS} / \mathrm{PAH})_{5} \text {-porous } \\
\text { alumina }\end{array}$ & Dip & 95 & 7.38 & $\begin{array}{c}4.8 \mathrm{bar}, 1000 \mathrm{ppm} \\
\mathrm{MgCl}_{2}\end{array}$ & {$[25]$} \\
\hline Polyamide & $\begin{array}{c}\text { Interfacial polymerization using } \\
\text { PEI/TMC }\end{array}$ & 92.2 & 2.8 & $\begin{array}{c}4 \text { bar, } 1000 \mathrm{ppm} \\
\mathrm{MgCl}_{2}\end{array}$ & {$[36]$} \\
\hline NF90 (Film Tech) & Interfacial polymerization & 89 & 4.37 & $\begin{array}{c}10 \text { bar, } 6600 \text { ppm } \\
\mathrm{MgCl}_{2}\end{array}$ & This work \\
\hline SBNF (Trisep) & Cellulose acetate & 86.14 & 1.62 & $\begin{array}{c}10 \text { bar, } 600 \text { ppm } \\
\mathrm{MgCl}_{2}\end{array}$ & {$[28]$} \\
\hline
\end{tabular}


stagnant afterward. It indicated that at that number of layers, the support has been completely covered.

3.3. Comparison with Other NF Membranes. In this section, the performance of our membrane is compared with other membranes either fabricated using LbL assembly or other techniques as can be seen in Table 1. As shown, membrane produced in this work is comparable to those membranes even when it was tested at $6600 \mathrm{ppm} \mathrm{MgCl}_{2}$, and the membrane still shows stable performance.

\section{Conclusions}

In this study, PEM TFC NF membranes consist of PEI/PSS were successfully fabricated using SA-LbL assembly. The fabricated membrane achieved comparable performance with commercial membrane such as NF90 which was tested at the same condition showed rejection rate of $89 \%$ and permeate permeability of $4.37 \mathrm{~L} / \mathrm{h} \mathrm{bar} \cdot \mathrm{m}^{2}$. Meanwhile, (PEI/ PSS $)_{10}-0.05$ achieved rejection rate of $93.95 \%$ and permeate permeability of $0.9 \mathrm{~L} / \mathrm{h} \mathrm{bar} \cdot \mathrm{m}^{2}$.

In conclusion, the proposed membrane fabrication method is promising, as this method is not limited to a certain type of material. A range of materials, including organic and inorganic materials and even microorganisms have been employed to create thin layers using the conventional dip-LbL assembly technique for various applications. There is still huge room for study and research in this type of membrane including optimization of preparation condition, selection of membrane materials, stability, and so on. Thus, the participation from researchers all over the world is urgently required.

\section{Data Availability}

All the data that support the findings of this study are displayed in this manuscript.

\section{Conflicts of Interest}

The author declares no conflicts of interest.

\section{Acknowledgments}

This project was funded by the National Plan for Science, Technology, and Innovation (MAARIFAH), King Abdulaziz City for Science and Technology, the Kingdome of Saudi Arabia, award \#: WAT68-08-R. The author also acknowledges Dr. Farid Fadhillah for his valuable analysis and discussion.

\section{References}

[1] B. Van der Bruggen, A. Koninckx, and C. Vandecasteele, "Separation of monovalent and divalent ions from aqueous solution by electrodialysis and nanofiltration," Water Research, vol. 38, no. 5, pp. 1347-1353, 2004.

[2] K. Gu, S. Wang, Y. Li, X. Zhao, Y. Zhou, and C. Gao, "A facile preparation of positively charged composite nanofiltration membrane with high selectivity and permeability," Journal of Membrane Science, vol. 581, pp. 214-223, 2019.

[3] X.-Y. Gong, Z.-H. Huang, H. Zhang et al., "Novel high-flux positively charged composite membrane incorporating titanium-based MOFs for heavy metal removal," Chemical Engineering Journal, vol. 398, Article ID 125706, 2020.

[4] B. A. M. Al-Rashdi, D. J. Johnson, and N. Hilal, "Removal of heavy metal ions by nanofiltration," Desalination, vol. 315, pp. 2-17, 2013.

[5] J. Tian, H. Chang, S. Gao, and R. Zhang, "How to fabricate a negatively charged NF membrane for heavy metal removal via the interfacial polymerization between PIP and TMC?" Desalination, vol. 491, Article ID 114499, 2020.

[6] K. V. Plakas and A. J. Karabelas, "Removal of pesticides from water by NF and RO membranes-a review," Desalination, vol. 287, pp. 255-265, 2012.

[7] H. Karimi, A. Rahimpour, and M. R. Shirzad Kebria, "Pesticides removal from water using modified piperazine-based nanofiltration (NF) membranes," Desalination and Water Treatment, vol. 57, no. 52, pp. 24844-24854, 2016.

[8] J. H. Mo, Y. H. Lee, J. Kim, J. Y. Jeong, and J. Jegal, “Treatment of dye aqueous solutions using nanofiltration polyamide composite membranes for the dye wastewater reuse," Dyes and Pigments, vol. 76, no. 2, pp. 429-434, 2008.

[9] A. Akbari, S. Desclaux, J. C. Remigy, and P. Aptel, "Treatment of textile dye effluents using a new photografted nanofiltration membrane," Desalination, vol. 149, no. 1-3, pp. 101-107, 2002.

[10] N. L. Le and S. P. Nunes, "Materials and membrane technologies for water and energy sustainability," Sustainable Materials and Technologies, vol. 7, pp. 1-28, 2016.

[11] K. P. Lee, T. C. Arnot, and D. Mattia, "A review of reverse osmosis membrane materials for desalination-development to date and future potential," Journal of Membrane Science, vol. 370, no. 1-2, pp. 1-22, 2011.

[12] R. J. Petersen, "Composite reverse osmosis and nanofiltration membranes," Journal of Membrane Science, vol. 83, no. 1, pp. 81-150, 1993.

[13] G. Decher, "Fuzzy nanoassemblies: toward layered polymeric multicomposites," Science, vol. 277, no. 5330, pp. 1232-1237, 1997.

[14] J. Cho, K. Char, J.-D. Hong, and K.-B. Lee, "Fabrication of highly ordered multilayer films using a spin self-assembly method," Advanced Materials, vol. 13, no. 14, pp. 1076-1078, 2001.

[15] P. A. Chiarelli, M. S. Johal, J. L. Casson, J. B. Roberts, J. M. Robinson, and H.-L. Wang, "Controlled fabrication of polyelectrolyte multilayer thin films using spin-assembly," Advanced Materials, vol. 13, no. 15, pp. 1167-1171, 2001.

[16] L. Krasemann and B. Tieke, "Selective ion transport across self-assembled alternating multilayers of cationic and anionic polyelectrolytes," Langmuir, vol. 16, no. 2, pp. 287-290, 2000.

[17] W. Jin, A. Toutianoush, and B. Tieke, "Use of polyelectrolyte layer-by-layer assemblies as nanofiltration and reverse osmosis membranes," Langmuir, vol. 19, no. 7, pp. 2550-2553, 2003.

[18] J. J. Harris, J. L. Stair, and M. L. Bruening, "Layered polyelectrolyte films as selective, ultrathin barriers for anion transport," Chemistry of Materials, vol. 12, no. 7, pp. 1941-1946, 2000.

[19] B. W. Stanton, J. J. Harris, M. D. Miller, and M. L. Bruening, "Ultrathin, multilayered polyelectrolyte films as nanofiltration membranes," Langmuir, vol. 19, no. 17, pp. 7038-7042, 2003.

[20] J. L. Stair, J. J. Harris, and M. L. Bruening, "Enhancement of the ion-transport selectivity of layered polyelectrolyte 
membranes through cross-linking and hybridization," Chemistry of Materials, vol. 13, no. 8, pp. 2641-2648, 2001.

[21] S. U. Hong, R. Malaisamy, and M. L. Bruening, "Optimization of flux and selectivity in $\mathrm{Cl}^{-} / \mathrm{SO}_{4}^{2-}$ separations with multilayer polyelectrolyte membranes," Journal of Membrane Science, vol. 283, no. 1-2, pp. 366-372, 2006.

[22] R. Malaisamy and M. L. Bruening, "High-flux nanofiltration membranes prepared by adsorption of multilayer polyelectrolyte membranes on polymeric supports," Langmuir, vol. 21, no. 23, pp. 10587-10592, 2005.

[23] H. Deng, Y. Xu, B. Zhu, X. Wei, F. Liu, and Z. Cui, "Polyelectrolyte membranes prepared by dynamic self-assembly of poly (4-styrenesulfonic acid-co-maleic acid) sodium salt (PSSMA) for nanofiltration (I)," Journal of Membrane Science, vol. 323, no. 1, pp. 125-133, 2008.

[24] Q. Nan, P. Li, and B. Cao, "Fabrication of positively charged nanofiltration membrane via the layer-by-layer assembly of graphene oxide and polyethylenimine for desalination," Applied Surface Science, vol. 387, pp. 521-528, 2016.

[25] L. Ouyang, R. Malaisamy, and M. L. Bruening, "Multilayer polyelectrolyte films as nanofiltration membranes for separating monovalent and divalent cations," Journal of Membrane Science, vol. 310, no. 1-2, pp. 76-84, 2008.

[26] F. Fadhillah, S. M. Javaid Zaidi, Z. Khan, M. Khaled, and P. T. Hammond, "Reverse osmosis desalination membrane formed from weak polyelectrolytes by spin assisted layer by layer technique," Desalination and Water Treatment, vol. 34, no. 1-3, pp. 44-49, 2011.

[27] F. Fadhillah, S. M. Javaid Zaidi, Z. Khan, M. Khaled, F. Rahman, and P. Hammond, "Development of multilayer polyelectrolyte thin-film membranes fabricated by spin assisted layer-by-layer assembly," Journal of Applied Polymer Science, vol. 126, no. 4, pp. 1468-1474, 2012.

[28] F. Fadhillah, A. M. Alghamdi, M. D. Alsubei, and S. A. Aljlil, "Synthesis of protein-fouling-resistance polyelectrolyte multilayered nanofiltration membranes through spin-assisted layer-by-layer assembly," Journal of King Saud University-Engineering Sciences, vol. 33, no. 2, pp. 81-87, 2021.

[29] A. M. Alghamdi and F. Fadhillah, "Thin film composite polyelectrolyte multilayer nanofiltration membrane fabricated using spin assisted layer by layer assembly: application of solution diffusion film model," Communications in Science and Technology, vol. 5, no. 1, pp. 10-15, 2020.

[30] K. S. Kim, K. H. Lee, K. Cho, and C. E. Park, "Surface modification of polysulfone ultrafiltration membrane by oxygen plasma treatment," Journal of Membrane Science, vol. 199, no. 1-2, pp. 135-145, 2002.

[31] A. Zhuk, V. Selin, I. Zhuk, B. Belov, J. F. Ankner, and S. A. Sukhishvili, "Chain conformation and dynamics in spinassisted weak polyelectrolyte multilayers," Langmuir, vol. 31, no. 13, pp. 3889-3896, 2015.

[32] J. E. Yoo, K. S. Lee, A. Garcia et al., "Directly patternable, highly conducting polymers for broad applications in organic electronics," Proceedings of the National Academy of Sciences, vol. 107, no. 13, pp. 5712-5717, 2010.

[33] C. Wu, L. Zhao, and Y. Zhang, "pH-responsive nanofiltration membranes based on porphyrin supramolecular self-assembly by layer-by-layer technique," RSC Advances, vol. 7, no. 75, pp. 47397-47406, 2017.

[34] J. L. Lutkenhaus, K. McEnnis, and P. T. Hammond, "Nanoand microporous layer-by-layer assemblies containing linear poly(ethylenimine) and poly(acrylic acid)," Macromolecules, vol. 41, no. 16, pp. 6047-6054, 2008.
[35] S. Singh, A. Junghans, M. J. Waltman, A. Nagy, R. Iyer, and J. Majewski, "Neutron reflectometry characterization of PEIPSS polyelectrolyte multilayers for cell culture," Soft Matter, vol. 8, no. 45, pp. 11484-11491, 2012.

[36] Y.-C. Chiang, Y.-Z. Hsub, R.-C. Ruaan, C.-J. Chuang, and K.-L. Tung, "Nanofiltration membranes synthesized from hyperbranched polyethyleneimine," Journal of Membrane Science, vol. 326, no. 1, pp. 19-26, 2009. 